\title{
Advances in therapeutic agents targeting quiescent cancer cells
}

\author{
Wan Najbah Nik Nabil ${ }^{a, b, 1}$, Zhichao Xij ${ }^{a, c, 1}$, Mengfan Liu ${ }^{a, c}$, Yang Li ${ }^{a, c}$, Mu Yao ${ }^{d, e}$, Tao Liuf, Qihan Dong ${ }^{d, e, *}$ \\ and Hongxi $X_{u^{g, a, *}}$ \\ aSchool of Pharmacy, Shanghai University of Traditional Chinese Medicine, Shanghai 201203, China \\ bPharmaceutical Services Program, Ministry of Health, Selangor 46200, Malaysia \\ 'Engineering Research Center of Shanghai Colleges for TCM New Drug Discovery, Shanghai 201203, China \\ ${ }^{\mathrm{d} C h i n e s e ~ M e d i c i n e ~ A n t i-C a n c e r ~ E v a l u a t i o n ~ P r o g r a m, ~ G r e g ~ B r o w n ~ L a b o r a t o r y, ~ C e n t r a l ~ C l i n i c a l ~ S c h o o l ~ a n d ~ C h a r l e s ~ P e r k i n s ~ C e n t r e, ~ T h e ~}$ \\ University of Sydney, Sydney 2060, Australia \\ eDepartment of Endocrinology, Royal Prince Alfred Hospital, Sydney 2050, Australia \\ ${ }^{f}$ Children's Cancer Institute Australia, Randwick Sydney, New South Wales 2031, Australia \\ gShuguang Hospital, Shanghai University of Traditional Chinese Medicine, Shanghai 201203, China \\ ${ }^{1}$ These authors contributed equally to this work and should be regarded as co-first authors. \\ *Correspondence: qihan.dong@sydney.edu.au (Q.D.); xuhongxi88@gmail.com (H.X.)
}

Received: 02 December 2021; Revised: 13 January 2022; Accepted: 15 January 2022

Published online: 08 February 2022

DOI 10.15212/AMM-2021-0005

\begin{abstract}
Quiescent cancer cells (QCCs) reversibly reside in $\mathrm{G}_{0}$ phase, thus allowing them to survive chemotherapy and radiotherapy, which generally target proliferating cells. Surviving QCCs may re-proliferate, and consequently result in cancer progression, recurrence, and metastasis. Therefore, understanding the key players governing QCC survival and activation is crucial for developing QCC-targeting agents. This review presents an overview of (1) the mechanisms underlying the regulation of QCC status and (2) recent advances in the development of QCC-targeting therapeutic agents and their underlying mechanisms. The development of effective therapeutic modalities that target QCCs may enable new cancer treatments to prevent cancer progression and recurrence.
\end{abstract}

Keywords: quiescence, dormancy, neoplasm, mechanism, therapeutic agent

\section{INTRODUCTION}

Cancer dormancy was first described in 1934, when autopsies of asymptomatic patients with cancer revealed overt metastases despite the absence of local recurrence; these findings indicated that cancer cells can be arrested in a dormant state [1, 2]. The two main types of cancer dormancy are tumour mass dormancy and cellular quiescence. In tumour mass dormancy, insufficient angiogenesis and immune surveillance in the tumour microenvironment sustain a dynamic balance between cancer cell proliferation and death within the tumour mass [3]. Cellular dormancy refers to quiescent cancer cells (QCCs), which are transiently arrested in the $\mathrm{G}_{0}$ phase but can re-enter the cell cycle and re-proliferate $[3,4]$. QCCs are present in various types of solid cancers, such as breast, lung, and prostate cancers, as well as in haematological malignancies [1]. Disseminated tumour cells (DTCs) and circulating tumour cells (CTCs) can be in any phase of the cell cycle, and only some of them remain in the quiescent state [5]. Similarly, cancer stem cells can be either quiescent or slowly proliferating [1, 3]. This review focuses on cancer cells in $G_{0}$ phase and does not specify the sources of these $G_{0}$ cells.

QCCs are detrimental because they attenuate the effects of treatment and promote cancer progression. The quiescent state enables QCCs to withstand conventional cancer treatments, because most therapies target proliferating cells [2]. Subsequently, the surviving QCCs lead to cancer progression via cell cycle re-entry. Quiescent CTCs and DTCs that survive in the bloodstream and settle at secondary sites, later initiate cancer recurrence and metastasis after they are activated to re-proliferate $[5,6]$. The application of QCC preclinical experimental models and detection methods has expanded understanding of QCC biology in recent years [7]. However, QCC-targeting agents are not yet clinically available. Therefore, both preclinical and clinical data on QCC agents are needed to identify potential targets and clinical strategies for developing effective therapeutic agents. We conducted electronic searches of the PubMed, Science Direct and Scopus databases from their 
inception to September 2021, by using the keywords 'neoplasm', 'cancer', 'tumour', 'quiescence', 'quiescent', 'dormancy', and 'dormant'. Articles that described preclinical and clinical studies on QCC-targeting agents were included. The extracted data included the names of potential agents, types of cancer/cell lines, efficacy, and mechanism of action. A table summarising the key findings is included for reference. Furthermore, we provide an overview of the mechanisms through which these QCC-targeting agents affect QCCs.

\section{MECHANISMS OF CELLULAR QUIESCENCE}

Multiple signalling pathways and interactions between cancer cells and the microenvironment niche determine whether cancer cells remain in or exit the quiescent state (Figure 1). Complex QCC mechanisms and networks not only promote drug resistance and tumour initiation, but also may indicate potential avenues for cancer treatment $[2,3,8,9]$. Accordingly, this section discusses initiation and termination mechanisms of quiescence (Figure 1), which are essential for understanding QCC-targeting agents (Table 1).

\subsection{Cyclin-dependent kinase (CDK) signalling pathways}

In the cell cycle machinery, the retinoblastoma protein (Rb) maintains cells in a quiescent state $\left(G_{0}\right.$ phase) by suppressing E2F family members, which control the transcription of genes regulating cell cycle progression $[34,35]$. Additionally, dimerisation partner (DP), Rb, E2F, and multivulval class $B$ (MuvB) form the DREAM complex, which keeps cells in $\mathrm{G}_{0}$ phase by suppressing the expression of genes required for cell cycle entry [36]. Mitogens initiate quiescent cells' re-entry into the cell cycle by stimulating the binding of cyclins to CDKs, and the subsequent inactivation of Rb through phosphorylation and the release of E2F protein [34, 37]. Cyclin C governs the transition from $G_{0}$ to $G_{1}$; cyclin $D$ modulates the $G_{1}$ phase; and cyclin $E$ regulates the late $G_{1}$ and $G_{1}-S$ transition. The cyclin E-CDK2 complex drives cell cycle progression by inhibiting the ubiquitinating enzyme anaphase-promoting complex (APC), thus increasing CDC6, a regulator of early stages of DNA replication. In contrast, CDC6 is depleted in quiescent cells [37].

The cell cycle also progresses when E2F promotes the expression of CDC6 mRNA, and the accumulated CDC6 represses the transcription of INK4, a CDK inhibitor (CDKI) towards CDK4 and CDK6 $[38,39]$. CDKIs in the Cip/Kip protein family comprise p21, p27, and p57, which bind and inactivate the CDK1/2/3-cyclin complex [34]. Quiescent cells have elevated levels of CDKIs, which prevent CDK activation and impede cell cycle progression [4, 34], such as through the upregulation of p57 by glucocorticoid receptors in quiescent lung cancer cells [40].

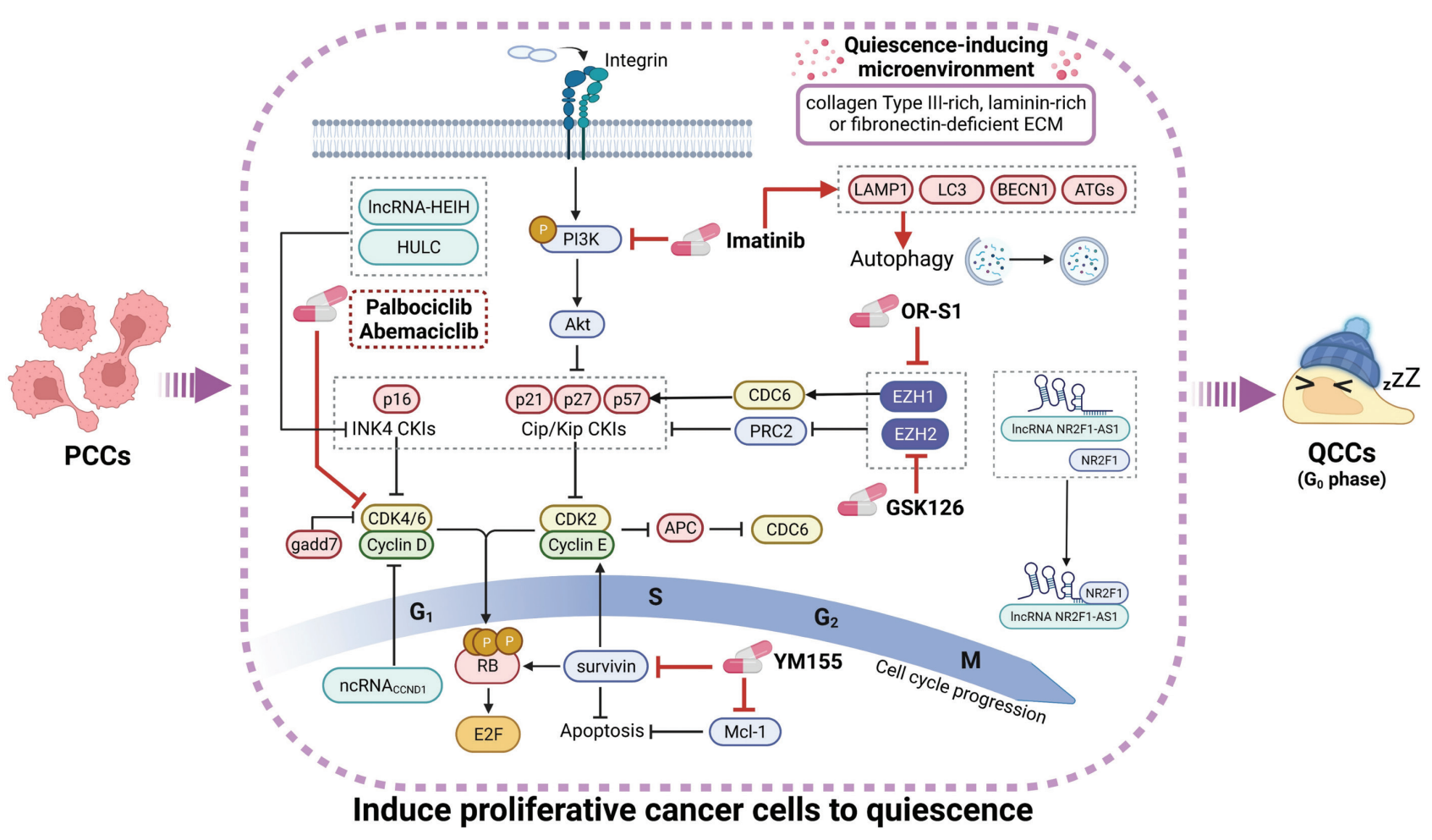

Figure 1 | Major mechanisms and agents that induce proliferative cancer cells to quiescence.

' $\uparrow$ ' represents activation, promotion, stimulation, or up-regulation, whereas ' $T$ ' represents inhibition, suppression, decrease, or downregulation. 
Table 1 | Preclinical findings for potential agents targeting quiescent cancer cells (QCCs)

\begin{tabular}{|c|c|c|c|c|}
\hline Potential agent & Cancer cell line & Mechanism & $\begin{array}{l}\text { Main action } \\
\text { on QCCs }\end{array}$ & References \\
\hline $\begin{array}{l}\text { Palbociclib } \\
\text { (breast cancer) }\end{array}$ & $\begin{array}{l}\text { Patient-derived PDAC cells (TKCC- } \\
\text { 02-19, TKCC-22-23, TKCC-26, TKCC- } \\
\text { 27); patient-derived glioma stem cells } \\
(\mathrm{G02}, \mathrm{G} 07, \mathrm{G} 08, \mathrm{G} 09)\end{array}$ & $\begin{array}{l}\text { - Inhibit CDK4/6, Rb phosphorylation, } \\
\text { E2F transcription, disassembly of } \\
\text { DREAM complex }\end{array}$ & $\begin{array}{l}\text { Induce } \\
\text { quiescence }\end{array}$ & {$[10-12]$} \\
\hline $\begin{array}{l}\text { Abemaciclib } \\
\text { (breast cancer) }\end{array}$ & $\begin{array}{l}\text { Ewing's sarcoma (A673, SK-ES-1, } \\
R D-E S, S K-N-M C)\end{array}$ & $\begin{array}{l}\text { - Inhibit CDK4/6, Rb phosphorylation, } \\
\text { E2F transcription, disassembly of } \\
\text { DREAM complex }\end{array}$ & $\begin{array}{l}\text { Induce } \\
\text { quiescence }\end{array}$ & [13] \\
\hline $\begin{array}{l}\text { Imatinib } \\
(C M L, A L L, G I S T S)\end{array}$ & GIST (GIST882, GIST-T1) & $\begin{array}{l}\text { - Inhibit PI3KIAKT pathway, SKP2 } \\
\text { - Induce p27, DREAM formation, } \\
\text { autophagy }\end{array}$ & $\begin{array}{l}\text { Induce } \\
\text { quiescence }\end{array}$ & [14-16]. \\
\hline GSK126 & $\begin{array}{l}\text { Castration-resistant prostate cancer } \\
\text { cells ( } 22 \text { Rv1 cells, C4-2B cells), DLBCL } \\
\text { (KARPAS- } 422 \text { cells) }\end{array}$ & Inhibit EZH2 & $\begin{array}{l}\text { Induce } \\
\text { quiescence }\end{array}$ & {$[17,18]$} \\
\hline OR-S1 & MCL (Mino, JeKo-1, REC-1) & $\begin{array}{l}\text { - Inhibit EZH 1/2, Rb phosphorylation } \\
\text { - Induce p57 }\end{array}$ & $\begin{array}{l}\text { Induce } \\
\text { quiescence }\end{array}$ & [19] \\
\hline $\begin{array}{l}\text { ATRA (acute } \\
\text { promyelocytic } \\
\text { leukaemia) }\end{array}$ & $\begin{array}{l}\text { Co-culture of pancreatic (AsPc1, } \\
\text { Capan1) and } \\
\text { pancreatic stellate cells (PS1); hepatic } \\
\text { stellate cells (HHStec 5300) }\end{array}$ & $\begin{array}{l}\text { - Alter cancer cell microenvironment to } \\
\text { induce quiescence }\end{array}$ & $\begin{array}{l}\text { Induce } \\
\text { quiescence }\end{array}$ & {$[20,21]$} \\
\hline $\begin{array}{l}\text { Sepantronium bromide } \\
\text { (YM155) }\end{array}$ & $\begin{array}{l}\text { Bladder transitional cell carcinoma } \\
\text { (BFTC905, T24, TSGH8301), kidney } \\
\text { transitional cell carcinoma (BFTC909), } \\
\text { multiple myeloma (U266, RPMI8226) } \\
\text { cells }\end{array}$ & $\begin{array}{l}\text { - Inhibit survivin, cyclin D, CDK4/6, } \\
\text { Mcl-1 } \\
\text { - Induce p27 }\end{array}$ & $\begin{array}{l}\text { Induce } \\
\text { quiescence }\end{array}$ & {$[22,23]$} \\
\hline Guttiferone K & Prostate (LNCaP, PC-3) & $\begin{array}{l}\text { - Inhibit c-MYC, } \\
\text { - Induce FBXW7, p27 }\end{array}$ & $\begin{array}{l}\text { Block cell cycle } \\
\text { re-entry }\end{array}$ & {$[24]$} \\
\hline Safranal & Prostate (LNCaP, PC-3) & $\begin{array}{l}\text { - Inhibit Skp2, NF-kB signalling, E2F1, } \\
\text { c-MYC, CDK2/4/6 } \\
\text { - Induce p21, p27 }\end{array}$ & $\begin{array}{l}\text { Block cell cycle } \\
\text { re-entry }\end{array}$ & [25] \\
\hline VLX600 & Colon (HCT116) & $\begin{array}{l}\text { - Inhibit OXPHOS } \\
\text { - Induce autophagy, apoptosis }\end{array}$ & $\begin{array}{l}\text { Eradicate } \\
\text { QCCS }\end{array}$ & [26] \\
\hline ESI-09 & NSCLC (A549, H1299, H1975, PC3) & $\begin{array}{l}\text { - Inhibit OXPHOS } \\
\text { - Induce apoptosis, necrosis }\end{array}$ & $\begin{array}{l}\text { Eradicate } \\
\text { QCCs }\end{array}$ & [27] \\
\hline $\begin{array}{l}\text { AZD7762/AZD6244 } \\
\text { (thyroid cancer, } \\
\text { neurofibromatosis), or } \\
\text { PD184352/CEP3891 }\end{array}$ & $\begin{array}{l}\text { Multiple myeloma } \\
\text { (NCI-H929, U266, RPMI 8226, } \\
\text { ANBL-6, KAS-6/1) }\end{array}$ & $\begin{array}{l}\text { - Inhibit Chk1, MEK1/2 } \\
\text { - Induce Bim, DNA damage, apoptosis }\end{array}$ & $\begin{array}{l}\text { Eradicate } \\
\text { QCCs }\end{array}$ & [28] \\
\hline $\begin{array}{l}\text { Clofazimine (leprosy, } \\
\text { tuberculosis) }\end{array}$ & CML (K562) & $\begin{array}{l}\text { - Inhibit Bcl-2 } \\
\text { - Induce apoptosis }\end{array}$ & $\begin{array}{l}\text { Eradicate } \\
\text { QCCs }\end{array}$ & [29] \\
\hline Compound A & $\begin{array}{l}\text { Colon (SW620), } \\
\text { Pancreatic (AsPc1, Panc1, SU86.86) }\end{array}$ & $\begin{array}{l}\text { - Inhibit DYRK1B, p27 } \\
\text { - Induce cyclin D, Rb, ROS production, } \\
\text { apoptosis }\end{array}$ & $\begin{array}{l}\text { Induce } \\
\text { cell cycle re- } \\
\text { entry }\end{array}$ & [30] \\
\hline ЕНT5372 & $\begin{array}{l}\text { Ovarian (OVCAR3, SKOV3), } \\
\text { pancreatic (Panc1) }\end{array}$ & $\begin{array}{l}\text { - Inhibit DYRK1B, p27 } \\
\text { - Induce cyclin D, Rb, ROS production, } \\
\text { apoptosis }\end{array}$ & $\begin{array}{l}\text { Induce } \\
\text { cell cycle re- } \\
\text { entry }\end{array}$ & {$[31,32]$} \\
\hline R05454948 & Ovarian (TOV21G, SKOV3) & $\begin{array}{l}\text { - Inhibit DYRK1B, p27 } \\
\text { - Induce cyclin D, ROS production, } \\
\text { apoptosis }\end{array}$ & $\begin{array}{l}\text { Induce } \\
\text { cell cycle re- } \\
\text { entry }\end{array}$ & [33] \\
\hline
\end{tabular}

Italic text indicates drugs used clinically for the selected disease (in brackets), whereas non-italic text indicates drugs under study. 


\subsection{Regulation of CDKIs and cyclins}

SKP1/Cullin 1/F-box (SCF) and anaphase-promoting complex/cyclosome (APC/C) are two major protein complexes regulating the cell cycle through the degradation of CDKIs and cyclins. APC/C is active in $G_{1}$ phase, whereas SCF modulates the $G_{1}, S$, and early $M$ phases. Within the SCF protein complex, F-box proteins specify the targets of the SCF domain. F-box proteins with WD40 domains (FBXW), such as FBXW7, trigger the degradation of Cyclin E, whereas S-phase kinase-associated protein 2 (SKP2) is an F-box protein that selectively degrades p21, p27, and p57. Interestingly, APC/C prevents p27 from being downregulated by promoting the degradation of SKP2, thereby sustaining the quiescent state [41].

Proteins such as survivin and Polycomb repressive complex 2 (PRC2) have multiple roles in cells, including controlling the cell cycle machinery. Survivin belongs to the inhibitor of apoptosis (IAP) protein family, and its expression oscillates throughout the cell cycle, with lower levels in $G_{1}$ phase and higher levels in $S$ phase. Cell cycle progression is accelerated in survivin-overexpressing cells, because survivin increases phosphorylated-Rb levels and the formation of the Cyclin E-CDK2 complex, decreases p27 protein expression levels, and antagonises $\mathrm{p} 16$ (an inhibitor of CDK4/6-Cyclin D) by displacing it from the CDK4-p16 complex [42].

Another protein family essential to the cell cycle is PRC2, which comprises the subunit enhancer of Zeste homologue 1 (EZH1) and enhancer of Zeste homologue 2 (EZH2). Both EZHs catalyse PRC2 activity, thus acting as epigenetic regulators suppressing the transcription of target genes, such as those encoding p15, p16, p21, and p27 [43, 44]. EZH2 knockdown in cholangiocarcinoma and glioma cells causes arrest in $\mathrm{G}_{0} / \mathrm{G}_{1}$ phase, and is accompanied by an increase in p16 and p27 transcription and downregulation of cyclin D and CDK4/6 protein levels $[44,45]$.

\section{3 c-Myc and related signalling pathways}

The oncogenic transcription factor c-Myc is highly expressed in solid tumours and haematological malignancies. c-Myc stimulates cell cycle progression by promoting the activity of cyclins and CDK, and disrupts the activity of CDKIs, which function as cell cycle 'brakes' [46]. c-Myc is upregulated by facilitates chromatin transcription factor (FACT) and is degraded by FBXW7 when cells exit quiescence [24, 47]. c-Myc decreases the protein and mRNA levels of p27 by inducing SKP2 and the microRNA (miRNA) miR-221/222, which silence p27 mRNA [48]. Moreover, c-Myc deregulates quiescence through the activation of miR-17-5p, which disrupts p21 or overcomes the inhibitory effects of miR-26a, miR15a, miR-34a, and INK4 on cyclin D/E or CDK4/6 [48-51]. However, a preclinical study has indicated that quiescent melanoma cells express high levels of c-Myc and consequently promoting QCC survival through the activation of oxidative phosphorylation (OXPHOS), thus revealing the complex role of c-Myc in regulating QCCs [52].
Integrins act on the upstream of c-Myc and are activated through extracellular matrix (ECM) stiffness, cell adhesion signalling, urokinase-type plasminogen activator, fibronectin, and periostin [3, 53-55]. Integrins and growth-factor receptors stimulate focal adhesion kinase (FAK), which then activates the PI3K-AKT and RAS-MEK-ERK-MAPK signalling cascades [54]. These cascades drive cell cycle progression through upregulating c-Myc, and drive cell exit from quiescence through increasing cyclins and decreasing CDKIs [48, 54]. For example, DIRAS3 and Regulcalcin induce tumour dormancy partially by blocking RAS/MAPK signalling $[56,57]$. Activated FAK additionally supports cell cycle progression by repressing the transcriptional activity of p53, a transcriptional repressor of c-Myc [54, 58]. p53 is activated in response to DNA damage or p38 signalling, thus resulting in miR-145 induction and subsequent inhibition of c-Myc [50, 59].

Another noteworthy function of c-Myc involves an autoregulatory feedback loop among C-Myc, E2F, and miR-17/20: (i) C-Myc triggers transcription of E2F, (ii) E2F activates transcription of c-Myc, (iii) both c-Myc and E2F induce miR-17/20, and (iv) miR-17/20 restricts the translation of E2F mRNA, thereby repressing malignant cell transformation [60].

\subsection{Dual specificity tyrosine phosphorylation- regulated kinase 1B (DYRK1B)}

Certain cancers (such as pancreatic, ovarian, lung, and breast cancers), as well as serum- and mitogen-deprived cells, overexpress DYRK1B, which is also known as Mirk protein [61]. DYRK1B is a checkpoint kinase that regulates cellular exit from $\mathrm{G}_{0}$ [61]. In addition to destabilising cyclin D and promoting p27, DYRK1B activates MuvB; subsequently, MuvB participates in formation of the DREAM protein complex, which maintains cells in $\mathrm{G}_{0}$ phase. In addition, DYRK1B mitigates oxidative stress by upregulating antioxidant genes, thereby decreasing the intracellular production of reactive oxygen species (ROS) and ultimately sustaining the quiescent phase $[61,62]$.

\subsection{Non-coding RNAs (ncRNAs)}

Untranslated transcripts known as ncRNAs include microRNAs (miRNAs) and long non-coding RNAs (IncRNAs), and are classified according to their lengths. ncRNAs serve as either tumour promoters or suppressors, and are particularly dysregulated in cancer [63]. miRNAs and IncRNAs affect the transition from quiescence to proliferation by mediating the expression of cyclin, CDK, CDKI, E2F, and c-Myc. For example, H19 IncRNA hinders the translation of Rb; IncRNA-HEIH and HULC suppress INK4 and p21; gadd7 is involved in the degradation of CDK6 mRNA; and ncRNA ${ }_{C C N D 1}$ disrupts cyclin D transcription [64].

Quiescence is induced when activated p53 upregulates its downstream miRNAs, such as miR-27b-3p, miR-34a, miR-145, and miR-455-3p, and downregulates the miR-17-92 cluster, miR-15b-16-2, and miR-155, thus 
impeding multiple proliferative pathways. miRNAs also modulate quiescence by abolishing the proliferative signals triggered by c-Myc and E2F [48, 50, 65-68]. In addition, quiescence can be initiated by the binding of IncRNA NR2F1-AS1 to the nuclear receptor NR2F1 [69]. Interactions between ncRNAs and cell cycle regulators provide possible targets for future therapies.

\subsection{OXPHOS}

In contrast to proliferative cancer cells, which heavily depend on glycolysis, QCCs predominantly rely on OXPHOS for energy and survival. Because glycolysis is repressed in nutrient-starved cancer cells, and is accompanied by increased production of tricarboxylic acid, proliferative cancer cells die, whereas QCCs survive, owing to intensified OXPHOS activity [70, 71]. OXPHOS oxidises carbon molecules in the tricarboxylic acid cycle, thus generating energy and conferring resistance to nutrient deficiency and cancer treatment for QCCs. Additionally, because cancer treatments damage intracellular components, autophagy is activated and subsequently degrades the damaged components; consequently, accumulation of autophagy-derived metabolites leads to apoptosis of proliferative cancer cells. In contrast, QCCs endure cancer treatment, because OXPHOS eliminates autophagy-derived metabolites through oxidisation, thereby preventing the aggregation of autophagy-derived metabolites [70, 71]. Treating QCCs with OXPHOS inhibitors blocks the compensatory mechanism for energy generation and survival and results in apoptosis of QCCs [70, 72].

\subsection{Apoptosis}

Briefly, apoptosis is triggered through extrinsic and intrinsic pathways. B-cell lymphoma-2 (Bcl-2) family members and IAP proteins regulate the intrinsic pathways through caspase activity. The interactions among the three subfamilies of $\mathrm{Bcl}-2$ family proteins-anti-apoptotic proteins ( $\mathrm{BCl}-2, \mathrm{Mcl}-1, \mathrm{BCl}-\mathrm{Xl}$, and $\mathrm{BCl}-\mathrm{W}), \mathrm{BH}-$ only proteins (Bim, Bad, Noxa, and Puma) and pro-apoptotic mediators (Bax and Bak)—direct cells to undergo or survive apoptosis [73]. IAP proteins such as survivin (BIRC5), XIAP (BIRC4), and CIAP1 (BIRC2) suppress apoptosis by inhibiting caspase activity [74].

Similarly to proliferating cancer cells, QCCs also undergo apoptosis. Some QCC-targeting agents induce apoptosis in QCCs through a decrease in IAP proteins such as survivin, and anti-apoptotic proteins such as Mcl-1 [22]. Although the apoptotic mechanism of Compound $A$ in quiescent pancreatic cancer cells is not well understood, QCCs treated with Compound A have been found to be positive for apoptosis markers (cleavage of PARP and activation of Caspase-3) [30].

\subsection{Autophagy-induced quiescence}

Autophagy has dual functions in tumourigenesis, suppressing tumourigenesis in the initial stage of cancer but supporting tumourigenesis in later stages [75]. Through autophagy, damaged organelles are removed and nutrients are recycled, thus allowing cancer cells to quiescence and survive $[75,76]$. Preclinical studies on various cancer types and animal models have shown that autophagic activity intensifies as cancer cells become quiescent. As autophagy is activated in quiescent murine breast D2.0R cancer cells, compared with proliferative D2.0R cells, the expression of the autophagy markers LAMP1 and LC3 gradually increases [77]. Correspondingly, in vivo findings have validated that autophagy suppression in QCCs decreases tumour regrowth and metastatic burden, because the accumulation of damaged organelles and ROS causes QCCS to undergo apoptosis [77, 78]. Additionally, autophagy has been clinically confirmed in dormant cancer cells, as observed in specimens from patients with ovarian cancer who experienced complete clinical remission after surgery and chemotherapy [77]. The timing of administration of autophagy inhibitors is critical, because if these inhibitors are provided before chemotherapy, they impair the formation of QCCs and decrease autophagy [79].

In QCCs, the transcription of autophagy-related genes (ATGs), such as LC3, ATG4, ATG5, ATG7, and BECN1, is upregulated. The autophagy pathway involves ATG and AMPK signalling in the formation and maturation of autophagic vesicles, whereas the kinase mTOR regulates lysosomal degradation in the later steps of the autophagy pathway $[75,76,79]$.

\subsection{Quiescence-inducing microenvironment}

The microenvironment of cancer cells can be divided into quiescence-inducing and proliferation-permissive types. The quiescence-inducing microenvironment includes collagen type III-rich, laminin-rich, or fibronectin-deficient ECM; suppression of proliferative signals such as FAK, ERK, and PI3K; and elevation of p53, p21, p27, thrombospondin, osteopontin, C-X-C motif chemokine ligand-12 (CXCL12), transforming growth factor- $\beta 2$ (TGF $\beta 2$ ), Wnt5a, and bone morphogenetic protein (BMP4/7) [3, 9, 80-82]. QCCs and stromal cells produce collagen type III, whose binding to the receptor discoidin domain receptor tyrosine kinase (DDR1) activates the JAK2/STAT1 signalling pathway, which in turn upregulates the expression of the collagen gene $\operatorname{COL} 3 A 1$, thus causing cancer cells to become and remain quiescent [81]. In contrast, ROS, which are generated from chemotherapy and radiotherapy, activate TGF 32 and BMP4/7, which then induce cancer cells to undergo quiescence through the activation of the p38 pathway and suppression of the $\mathrm{Wnt} / \beta$-catenin signalling pathway, respectively $[82,83]$.

The proliferation-permissive microenvironment includes a collagen-rich (specifically collagen type I and IV) ECM, and the presence of Wnt ligands and activated proliferative signals, such as upregulated E2F and cyclin D [3, $9,80,84]$. In addition, receptor activation of NF- $\kappa \beta$ ligand (RANKL), which is expressed by cancer cells and aging osteoblasts, prompts quiescent DTCs to reactivate and 
re-proliferate, and consequently give rise to detectable metastasis [82]. Binding of Wnt to its receptor activates the $\mathrm{Wnt} / \mathrm{\beta}$-catenin signalling pathway, thereby preventing the degradation of $\beta$-catenin, and consequently upregulating the expression of c-Myc, cyclin D, CDK6, and other cell cycle-associated proteins. Blocking Wnt/Bcatenin signalling triggers quiescence in colorectal cancer cells [85]. When chronic myeloid leukaemia (CML) stem cells adapt to survive in secondary organs, elevated miR-126 and miR-300 in the bone marrow microenvironment stimulate the quiescence of CML stem cells $[67,86]$.

Additionally, microenvironmental components such as bone marrow mesenchymal stem cells protect breast cancer cells from immune clearance [87, 88]. Examination of bone marrow samples from patients with breast cancer has further confirmed the interaction between breast cancer cells and mesenchymal stem cells, and elucidated the importance of exosomes derived from mesenchymal stem cells in inducing breast cancer cells to undergo quiescence in the bone marrow perivascular niche [89]. Interestingly, although miR-222/223 in exosomes has been reported to induce quiescence [88], this finding contradicts other evidence suggesting that miR-221/222 activates CDK2 and downregulates p27 and p57, thus leading to cell proliferation $[48,50,66]$. Stellate cells, another major component of the tumour microenvironment, affect DTCs in the tissue-specific microenvironment. Although most DTCs that reside in liver tissue are quiescent, owing to the suppression effect of natural killer (NK) cells, liver injury activates secretion of CXCL12 by hepatic stellate cells, and consequently restricts the proliferation of NK cells and promotes the exit of DTCs from quiescence [90].

\section{DEVELOPMENT OF QCC-TARGETING THERAPEUTIC AGENTS}

Studies have highlighted the notable clinical implications of QCCs: tumours become chemoresistant, owing to QCCs [2], and recurrence and metastasis stem from reactivated QCCs $[5,6]$. To control QCCs and prevent cancer recurrence and metastasis, four types therapeutic strategies targeting QCCs have been described: a) inducing quiescence in proliferative cancer cells, b) blocking QCC re-proliferation, c) eradicating QCCs, and d) activating QCCs such that they succumb to conventional cancer treatment. The first two of these therapeutic strategies are aimed at proliferative and quiescent cancer cells, respectively, to induce and maintain cancer cells in quiescence. For rapidly proliferating cancer cells, inducing quiescence by repressing proliferative signals (such CDK, c-Myc, and ncRNA pathways) or promoting a quiescence-inducing microenvironment can suppress tumour growth and cancer progression (Figures 1 and 2) [37, 91, 92]. For cancer cells to remain quiescent, blocking QCCs from re-entry into the cell cycle prevents cancer

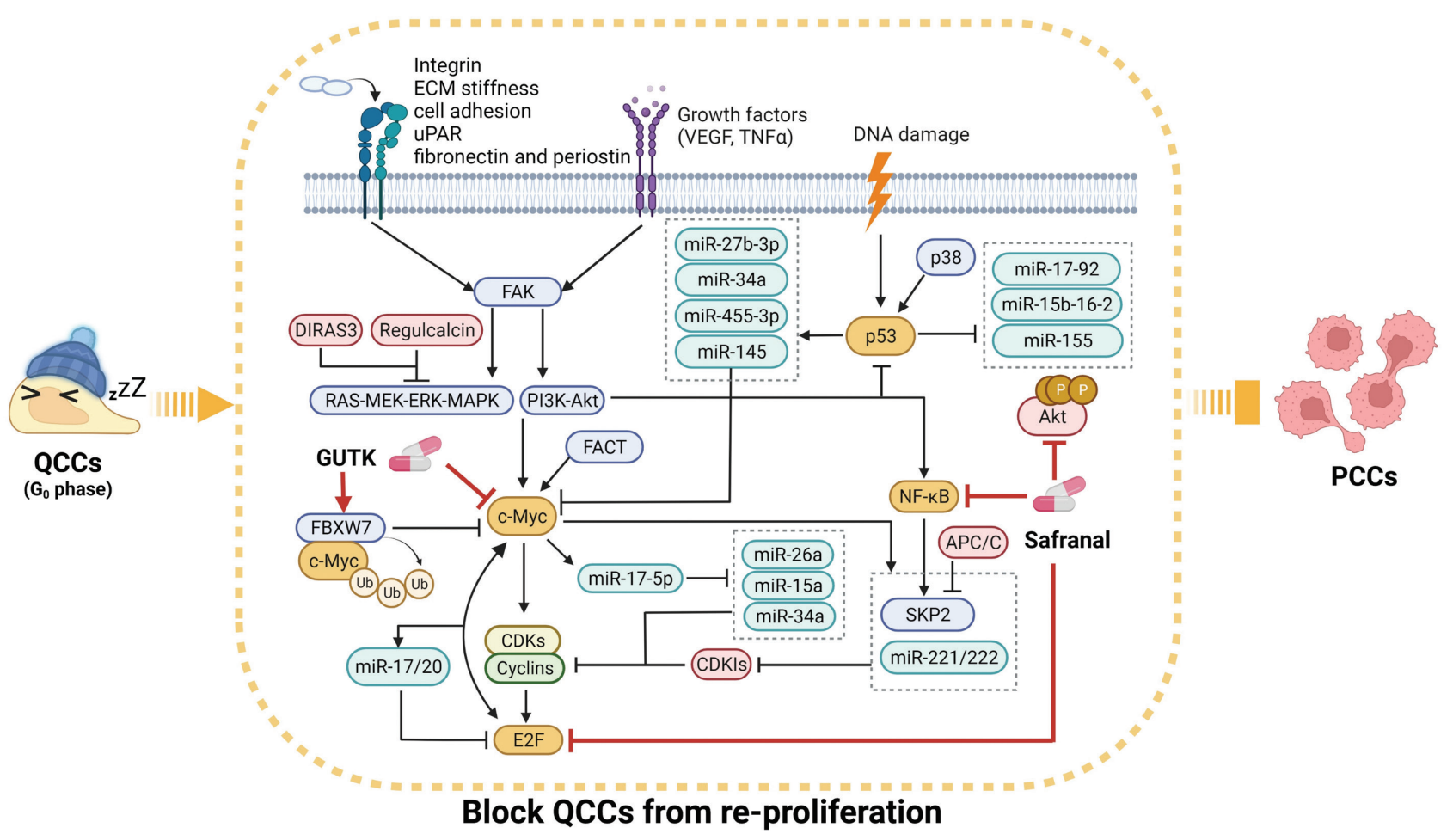

Figure 2 | Major mechanisms and agents that block quiescent cancer cells (QCCs) from re-proliferating

' $\uparrow$ ' represents activation, promotion, stimulation, or up-regulation, whereas ' $\mathrm{T}$ ' represents inhibition, suppression, decrease, or downregulation. 
recurrence by prolonging their stable quiescent state. Multiple molecules are involved in this mechanism, including c-Myc, FACT, and Mirk [2, 47, 92]. Because conventional cancer treatments generally kill proliferative cancer cells and spare QCCs, the third strategy involves eradicating QCCs through autophagic cell death or apoptosis, thus synergistically increasing the cancer treatment response (Figure 3) [26]. The fourth strategy, activating QCCs to re-enter the cell cycle, sensitises these cells to the cytotoxicity of conventional cancer treatments, thereby augmenting the treatment response (Figure 4) [61]. However, this treatment approach has been widely debated, because preclinical evidence has shown that activated QCCs may aggressively grow and cause metastasis at multiple sites [92]. Several clinically available and preclinically researched drugs with QCCtargeting actions are summarised according to their main QCC-targeting mechanisms (Figures 1-4). The related mechanisms of action and findings from clinical trials are also discussed. Of note, some QCC-targeting agents may have dual actions, e.g., disrupting the cell cycle and inducing death in QCCs.

\subsection{Agents inducing cancer cells to enter a quiescent state \\ 3.1.1 Palbociclib and abemaciclib}

Palbociclib is an inhibitor of CDK4/6 that can potentially treat pancreatic ductal adenocarcinoma (PDAC), because it drives pancreatic cancer cells to enter quiescence, thereby slowing tumour growth, suppressing metastasis, and prolonging survival [10]. Palbociclib and abemaciclib induce quiescence in glioma stem cells and Ewing sarcoma cells, respectively [11, 13].

By binding the ATP site on CDK4/6, palbociclib and abemaciclib suppress CDK4/6 function, thus decreasing $\mathrm{Rb}$ phosphorylation, dismantling the DREAM complex, and decreasing E2F transcription activity [93, 94]. Because cancer cells highly express Rb, [95], palbociclib and abemaciclib induce the quiescence of $\mathrm{Rb}$-expressing cancer cells. In addition, palbociclib induces apoptosis in $G_{0}$ cells, as evidenced by the elevated fraction of apoptotic $\mathrm{G}_{0}$ PDAC cells after palbociclib treatment compared with gemcitabine monotherapy $[10,13]$.

Clinically, palbociclib and abemaciclib are combined with endocrine therapy in patients with stage IV recurrent hormone-receptor-positive breast cancer. Compared with endocrine monotherapy, combination therapy extends progression-free survival (PFS) and improves the objective response rate (ORR) of treated patients [96]. Notably, abemaciclib is the only CDKI used as a monotherapy for treating patients with hormone-receptor-positive, epidermal growth factor receptor 2 (HER2)-negative breast cancer who are unresponsive to endocrine therapy and chemotherapy. Although a trial of palbociclib monotherapy in patients with metastatic refractory pancreatic neuroendocrine tumours (pNETs) did not achieve the trial endpoints

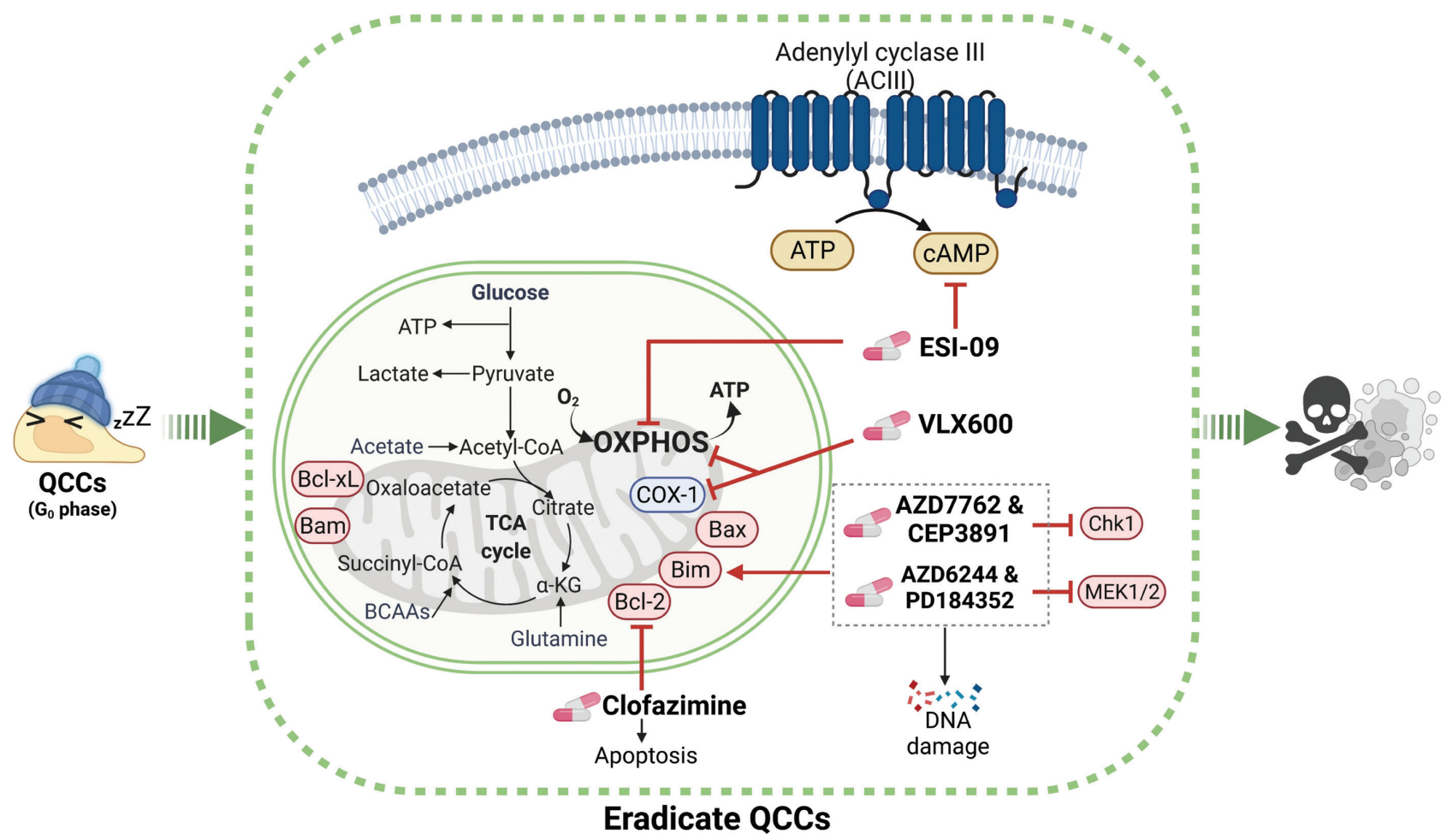

Figure 3 | Major mechanisms and agents that eradicate quiescent cancer cells (QCCs)

' $\uparrow$ ' represents activation, promotion, stimulation, or up-regulation, whereas ' $T$ ' represents inhibition, suppression, decrease, or downregulation. 


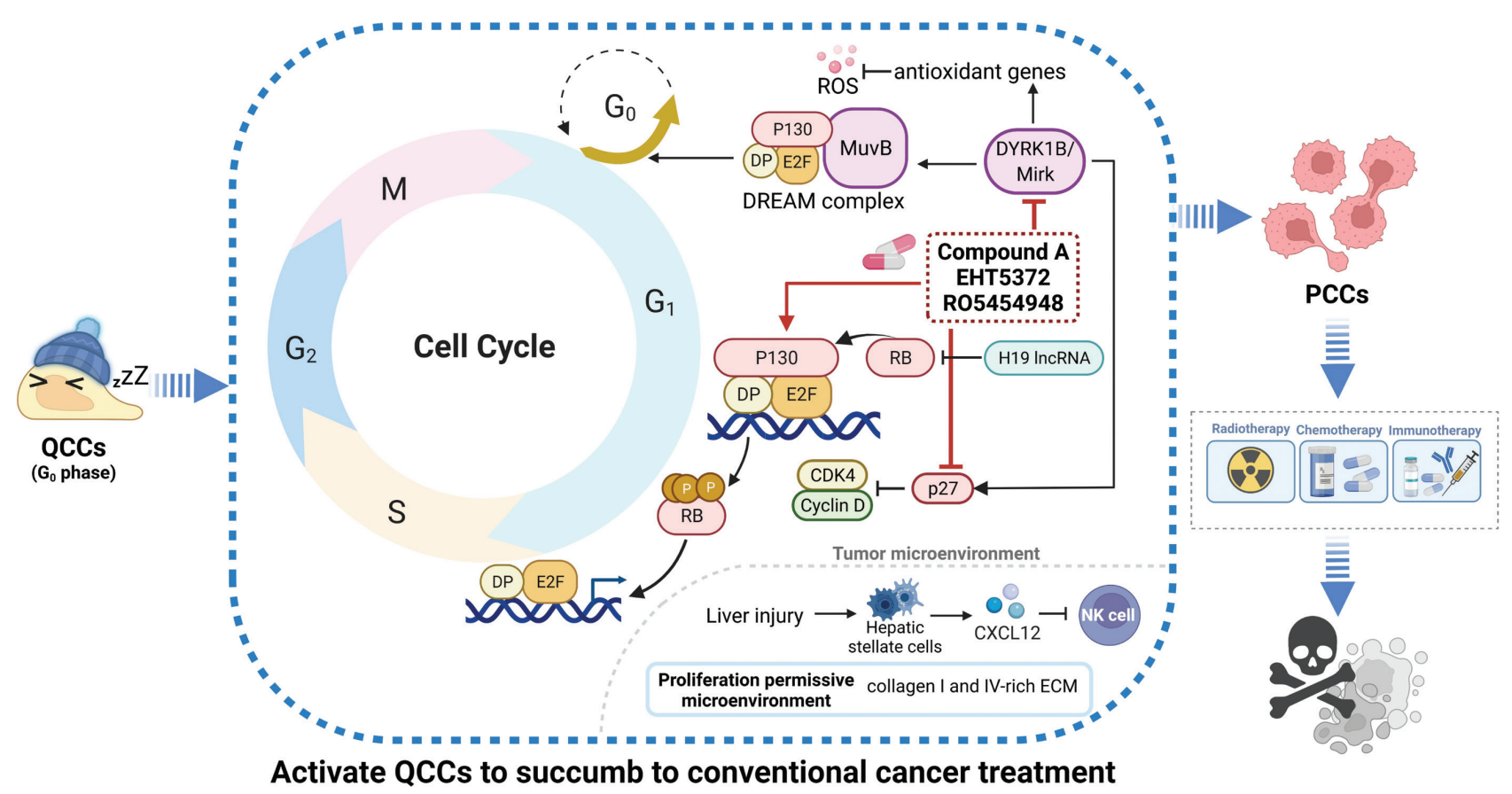

Figure 4 | Major mechanisms and agents that activate quiescent cancer cells (QCCs) and make them susceptible to conventional cancer treatment.

' $\uparrow$ ' represents activation, promotion, stimulation, or up-regulation, whereas ' $T$ ' represents inhibition, suppression, decrease, or downregulation.

of PFS and ORR, more than half $(57.9 \%)$ the patients remained stable. Ongoing clinical trials are examining the use of abemaciclib and palbociclib in other types of cancers, such as brain metastases and non-small cell lung cancer (NSCLC) [97].

\subsubsection{Imatinib}

Imatinib, a tyrosine kinase inhibitor, has been approved for the treatment of $C M L$, acute lymphoblastic leukaemia (ALL), and gastrointestinal stromal tumours (GISTs) [98]. Preclinical studies have revealed that imatinib triggers quiescence in GIST cells by promoting assembly of the DREAM complex, inhibiting the PI3K/AKT pathway, and activating autophagy [14-16]. Suppression of PI3K promotes APC/C degradation of SKP2, thus resulting in the accumulation of p27 $[14,15]$. Exposure to imatinib induces quiescence and autophagy in GIST cells, as indicated by increased formation of LC3 puncta. Concordantly, removing imatinib from GIST cells causes them to exit the quiescent state and expand the fraction of cells in $S / G_{2} / M$ phase [16].

A systematic review has corroborated that adjuvant therapy with imatinib improves the 1-year recurrence-free survival in patients with GIST $(98 \%)$ compared with those in the placebo arm $(83 \%)$ [99]. The single-arm PERSIST-5 clinical trial has shown that in patients with GIST with a significant risk of recurrence, 5 years of imatinib treatment after primary tumour resection increases the recurrence-free survival to $90 \%$ and the overall survival to $95 \%$. However, for patients in the control group in the EORTC 62024 trial, the 5-year recurrence-free survival rate was $63 \%$. Despite its tolerability and promise in preventing GIST recurrence, nearly half of the 91 recruited participants $(49 \%)$ discontinued imatinib before reaching the 5 -year duration (mainly because of patient choice). Of the 45 participants who discontinued imatinib, six experienced cancer recurrence (ranging from 7.4 to 23.1 months post-discontinuation), whereas only one patient developed recurrence while receiving imatinib treatment [100]. Therefore, patient compliance and suitable treatment duration require further examination to optimise the benefits.

\subsubsection{GSK126, OR-S1}

EZH2 is overexpressed in various cancer types including castration-resistant prostate cancer and diffuse large B-cell lymphoma (DLBCL). Cancer grows as a result of EZH2 blocking CDKIs, such as p16, p21, and p27, hence accelerating cancer cell proliferation [17, 18, 101]. The EZH2 inhibitor GSK126 disrupts EZH2 methyltransferase activity and releases PRC2 suppression of targeted genes by competing with $S$-adenosylmethionine for binding to EZH2, thus causing cell quiescence. Although GSK126 has progressed to a phase 1 clinical trial (NCT02082977), of the 22 enrolled patients with relapsed DLBCL, solid tumours, and other non-Hodgkin lymphomas, only one patient had a partial response, and seven remained stable [18]. 
Compared with GSK126, which inhibits only EZH2, OR-S1 is a novel dual inhibitor of EZH1 and EZH2 that fully impairs PRC2 activity and has higher anti-tumour activity than that of GSK126 in acute myeloid leukaemia, DLBCL, and mantle cell lymphoma (MCL) cells $[18,19]$. OR-S1 promotes quiescence in cancer cells by upregulating CDKN1C, which encodes p57 and blocks $\mathrm{Rb}$ phosphorylation. In vitro experiments have shown that OR-S1 causes $50 \%$ suppression of proliferation in MCL cell lines (Mino, JeKo-1, REC-1) at a dose less than one-tenth $(<100 \mathrm{nmol} / \mathrm{L})$ that of GSK126 (> 1,000 nmo$\mathrm{I} / \mathrm{L})$. After treatment of mice bearing $\mathrm{MCL}$ patient-derived xenografts with the new MCL drug ibrutinib, the tumour size has been found to reach nearly $40,000 \mathrm{~mm}^{3}$. Although one study has found that OR-S1 suppresses almost $90 \%$ of tumour growth, the treated mice survived only until study completion [19]. Despite its potential to induce quiescence in cancer cells and its in vivo tolerability, OR-S1 has yet to be clinically tested.

\subsubsection{All-trans retinoic acid (ATRA)}

ATRA is a derivative of vitamin A that has been clinically used for treating acute promyelocytic leukaemia [102] and can halt the progression of PDAC. Desmoplastic stroma, a prominent feature of PDAC, results from activated pancreatic stellate cells (PSCs) forming collagenand fibronectin-enriched ECM. Because the compact ECM that encloses pancreatic cancer cells constricts blood vessels, the delivery of therapeutic agents to cancer cells is obstructed, thus leading to tumour outgrowth, metastasis, and resistance to chemotherapy [103].

ATRA alters the microenvironment of pancreatic cancer cells by inducing quiescence of neighbouring PSCs and inhibiting the production of the ECM proteins (collagen and fibronectin) [20, 21]. Additionally, quiescent PSCs release secreted frizzled-related protein 4 (sFRP4), which has a paracrine effect on adjacent cancer cells. SFRP4 blocks the Wnt/ $\beta$-catenin signalling pathway in cancer cells and consequently impairs their proliferation [21, 80]. A phase I clinical trial has co-administered ATRA to all 27 enrolled patients with advanced and unresectable PDAC to normalise desmoplastic stroma, thus allowing gemcitabine and paclitaxel to penetrate the tumour tissues (NCT03307148). Given its tolerability and promising median overall survival (11.7 months; 95\% confidence interval: 8.6-15.7 months), ATRA is undergoing a phase II trial for locally advanced PDAC (NCT04241276) [104].

\subsubsection{Sepantronium bromide (YM155)}

YM155, an inhibitor of survivin, exploits survivin overexpression in various cancers. YM155 induces apoptosis and quiescence of cancer cells, and its cytotoxic action appears to preferentially act on cancer cells rather than normal cells $[22,23]$. Survivin promotes cell cycle progression by affecting cell cycle-regulatory proteins. Bladder transitional cell carcinoma cells treated with $20 \mathrm{nM}$ YM155 for $48 \mathrm{~h}$ have been found to accumulate more QCCs than control cells [23]. Another study has observed that after treatment of multiple myeloma (MM) U266 and RMPI8226 cells with YM155, the apoptotic $G_{0}$ cells expanded by $35.1 \%$ and $43.2 \%$, respectively, with respect to the findings for untreated cells. YM155 significantly represses the mRNA levels of survivin, as well as the protein expression of $\mathrm{Mcl}-1$ through proteasome degradation [22].

In vivo studies have reported that YM155 alone downregulates spontaneous metastasis in triple-negative breast cancer models. The addition of YM155 potentiates radiotherapy, chemotherapy, and monoclonal antibody therapy for NSCLC, melanoma, pancreatic cancer, and B-cell non-Hodgkin lymphoma [105]. However, clinical trials of YM155 as a monotherapy or combinatorial treatment in patients with cancer have shown low and non-durable anti-tumour efficacy, possibly because of the instability of YM155, which rapidly declines in the serum after the completion of treatment. Although modification of the YM155 structure may improve its stability and anti-tumour activity, recent clinical trials of LY2181308 (a survivin antisense oligonucleotide) have indicated that structural modifications have not improved PFS and overall survival [105]. Given the role of survivin in regulating QCCs, exploring survivin inhibitors with greater potency and stability should prove interesting.

\subsection{Agents blocking QCCs re-entry into the cell cycle}

\subsubsection{Guttiferone K (GUTK)}

GUTK, a polyprenylated acylphloroglucinol compound derived from Garcinia yunnanensis Hu., suppresses QCCs re-proliferation through c-MYC $[24,106]$. c-MYC protein levels are substantially lower in quiescent cells than in proliferative prostate cancer cells, and these levels rapidly increase during cell cycle re-entry. However, when cancer cells are released from quiescence, GUTK treatment stabilises FBXW7, the subunit of E3 ubiquitin ligase that degrades the c-MYC protein. Hence, the increase in c-MYC protein expression is repressed along with increased degradation by FBXW7. GUTK, administered either in vitro before transplantation or in vivo, retards the growth of quiescent prostate cancer cell xenografts [24]. Although a preclinical study has revealed the inhibitory actions of GUTK in QCCs, its clinical application in suppressing prostate cancer progression warrants further evaluation.

\subsubsection{Safranal}

Safranal, a monoterpene aldehyde from Crocus sativus, sustains prostate cancer cells in the quiescent state by suppressing the transcription of SKP2. The underlying mechanism involves downregulation of E2F1 and NF- $\kappa B$ at the transcriptional level, which in turn suppress the transcription of SKP2. Safranal additionally suppresses AKT phosphorylation and blocks both the canonical and noncanonical NF-KB signalling pathways. An in vivo study 
has revealed that Safranal stunts the tumour growth of quiescent prostate cancer cell xenografts; depletes SKP2, E2F1, NF-kB p65, p-lkBa (Ser32), c-MYC, p-Rb (Ser807), CDK4, CDK6, and CDK2; and causes accumulation of p27 and p21 proteins. This preclinical evidence indicates that by targeting the NF-KB/E2F1-SKP2 axis, safranal can counteract cancer recurrence and progression [25].

\subsection{Agents to eradicate QCCs}

\subsubsection{VLX600}

VLX600 eradicates QCCs by disrupting OXPHOS metabolism, particularly by downregulating the expression of mitochondrial cytochrome c oxidase-1 (COX$1)$, which is crucial for mitochondrial OXPHOS. The OXPHOS blockade undermines the metabolism of oxygen-deficient quiescent cells, which rely heavily on OXPHOS to generate energy and survive. Apoptosis has been found to be triggered in the core region (mainly comprising quiescent cells) in 3D colon cancer cell culture after $72 \mathrm{~h}$ of VLX600 treatment, and the core region becomes necrotic with longer treatment durations. In addition to inhibiting OXPHOS, autophagy is progressively activated from $24 \mathrm{~h}$ onwards in the core of in 3D cultured VLX600-treated cells, thus suggesting the activation of autophagic cell death. Compared with monolayer cell culture, the application of 3D cell culture more closely mimics solid tumours that grow in three dimensions, such as the nutrient- and oxygen-deprived microenvironment, as observed in the hypovascularised tumours associated with higher drug resistance, restricted drug penetration, and altered drug response [26]. A phase 1 trial of VLX600 monotherapy in patients with refractory advanced solid tumours was terminated early, owing to low patient recruitment. Although the clinical efficacy of VLX600 could not be assessed [107], laboratory findings regarding VLX600 have provided evidence that targeting OXPHOS may potentially eliminate QCCs.

\subsubsection{ESI-09}

ESI-09, a synthetic compound initially found to inhibit CAMP receptors, has recently been revealed to have preferential cytotoxicity towards quiescent NSCLC cells by blocking OXPHOS through disruption of the proton gradient across the mitochondrial inner membrane $[27,108]$. Exposure to ESI-09 increases cell death in the core region in $3 \mathrm{D}$ culture, as well as serum-deprived quiescent NSCLC cells in 2D culture, and suppresses tumour growth in mice bearing lung tumours. Cell death in serum-deprived quiescent 2D culture occurs through apoptosis and necrosis, whereas necrotic lesions have been observed in the tumour sections of ESI-09-treated mice [27]. Despite the positive preclinical findings, ESI09 faces challenges for clinical use, owing to its narrow therapeutic window and its potential to decrease the viability of quiescent normal cells [27].

\subsubsection{AZD7762, AZD6244, PD184352, CEP3891}

AZD7762 and CEP3891 are Chk1 inhibitors, whereas AZD6244 and PD184352 are MEK1/2 inhibitors [28]. AZD6244 has been marketed as selumetinib and approved for the treatment of thyroid cancer and neurofibromatosis [109]. Combinatorial AZD7762/AZD6224 and CEP3891/PD184352 treatment in quiescent multiple myeloma RPMI8226 cells induces DNA damage and causes $40 \%$ and $51 \%$ cell apoptosis, respectively. The lethal effect is due to the significant upregulation of the pro-apoptotic protein Bim in quiescent MM cells. This combination treatment preferentially eradicates both proliferating and quiescent MM cells without affecting normal haematopoietic cells [28]. A phase II trial in patients with relapsed or refractory MM has shown that AZD6244 monotherapy is well tolerated. However, the clinical response in that study was insignificant, possibly because of the heavily pre-treated population, thus suggesting that suitable selection of a patient population is critical for apparent anti-tumour activity [110].

\subsubsection{Clofazimine}

Clofazimine is a clinically effective drug used for the treatment of leprosy and multi-drug-resistant tuberculosis. Recent evidence has indicated that clofazimine induces apoptosis in quiescent leukaemia stem cells (LSCS) in vivo, without harming normal haematopoietic stem cells. Clofazimine induces apoptosis in quiescent LSCs by blocking the transcription and translation of $\mathrm{BCl}-$ 2. Co-administration of clofazimine with imatinib for 96 $\mathrm{h}$ almost completely eradicates LSCs by intensifying the apoptosis of both quiescent and proliferative LSCs [29]. These findings support the potential use of clofazimine in specifically targeting quiescent LSCs.

\subsection{Agents inducing QCC re-entry into the cell cycle and susceptibility to cancer treatment}

Mirk kinase inhibitors, namely Compound A, EHT5372, and RO5454948, promote colon, ovarian, and pancreatic QCC re-entry into the cell cycle and prevent proliferative cancer cells from entering quiescence. These inhibitors trigger the cell cycle re-entry of QCCs by increasing the levels of cyclin D and p130/Rb2 and downregulating p27. Additionally, ROS levels in QCCs increase after treatment with Compound A, EHT5372, or R05454948, thereby causing DNA damage and apoptosis [30-33]. Gemcitabine elevates ROS levels, and co-treatment of QCCs with Compound A potentiates the toxicity of gemcitabine by further increasing ROS levels. After exposure of serum-deprived Panc1 cells ( $59 \%$ in $G_{0}$ phase) to Compound A and serum replenishment, intracelIular cyclin D is upregulated, leaving only $27 \%$ of cells in $G_{0}$ phase. However, only replenishing the serum in serum-deprived Panc1 cells results in retention of $42 \%$ of the $G_{0}$ cells [30]. Notably, Mirk kinase inhibitors do not exert these effects in quiescent normal cells, which have very low levels of DYRK1B, thus indicating that 
their toxicity is confined to cancer cells and highlighting their cancer selectivity properties [30,33]. However, limited in vivo studies have examined Mirk kinase inhibitors. EHT5372 significantly decreases tumour size and prolongs the survival in xenografted mice, whereas the instability of RO5454948 in mice has hindered in vivo study [32].

\section{DISCUSSION}

Despite advances in cancer treatment, metastasis, and recurrence resulting from QCCs remain major causes of cancer mortality [6]. However, treatments relying solely on QCC-targeting agents face clinical issues, given that tumours are heterogeneously composed of both proliferative cancer cells and QCCs. Therefore, the treatment response can be optimised by combining conventional cancer treatments, which mainly target proliferative cancer cells, with QCC-targeting agents [2, 26, 92]. Triggering QCC re-entry into the cell cycle sensitises them to the cytotoxic action of chemotherapy, thereby potentiating the tumour response to chemotherapy [30, 111]. After conventional cancer treatments that are cytotoxic to proliferative cancer cells, inducing cancer cells to enter quiescence prolongs survival and disrupts in vivo tumour growth [10]. This treatment strategy could suppress cancer recurrence and metastases in patients with cancer, particularly those with special considerations, such as those who are pregnant and expected to give birth after cancer treatment, or those with unresectable tumours. Suppressing QCC re-entry into the cell cycle may repress their re-proliferation and consequently prevent cancer metastasis and recurrence [112].

Clinically available QCC-targeting agents remain to be optimised. Currently, only CDKIs are used to delay the progression of advanced-stage breast cancer. Preclinical studies have identified potential therapeutic agents that induce/maintain or eradicate QCCs. However, hurdles have hindered progress in clinical studies and bedside applications. The efficacy and safety of QCC-targeting agents as monotherapies or in combination treatments must be clinically tested, thus prolonging the development process. Potential agents such as VLX600, which act on both proliferative and quiescent cancer cells, are ideal candidates for cancer monotherapy and avoid concerns regarding adverse events arising from combinatorial treatment. However, clinical trials of VLX600 have not been conducted, owing to the long duration and difficulties in recruiting sufficient numbers of patients with advanced-stage cancer [107].

Additional challenges in using QCC-targeting agents to suppress cancer recurrence and metastasis include patient safety, compliance, tolerability, and cost concerns, which increase with treatment duration. Because QCCs may remain latent in the body for prolonged periods, patients may require lifelong treatment with agents to block QCC reactivation and avoid cancer progression [91]. For example, although imatinib has been clinically applied for haematological malignancies and GISTs [98], no complete trial has examined the use of imatinib for more than 5 years. A phase II study (NCT05009927) evaluating the progression-free rate, overall survival, and safety profile of 10-year imatinib treatment is expected to be completed in October 2024. The findings on the long-term use of imatinib are expected to support its potential QCC-inducing use for prolonged periods.

Taking advantage of certain enzymes or proteins that are overexpressed in cancer cells but are absent in normal cells, or vice versa, may explain the selectivity of QCC-targeting agents such as VLX600 and YM155. By inhibiting OXPHOS and increasing AMPK phosphorylation, VLX600 preferentially kills quiescent colon cancer HCT116 cells but spares normal quiescent epithelial hTERT-RPE1 cells with unobservable systemic toxicity in xenografted mice. Its selective action on QCCs is attributable to the absence of AMPK phosphorylation and the presence of glycolysis, thus supplementing energy in normal cells [26]. As a survivin inhibitor, YM155 induces bladder transitional cell carcinoma to quiescence, while sparing normal human urothelial cells, which have substantially lower survivin expression than cancer cells [23]. In contrast, QCC-targeting agents may cause adverse effects when their selectivity decreases, owing to overlapping expression of the targeted protein or enzyme in cancer and normal cells. One such agent is RO5454948, which induces QCC reactivation through inhibition of the Mirk protein. Although Mirk is commonly overexpressed in cancer cells compared with normal cells, clinical samples have shown that Mirk expression is significantly upregulated in ovarian tumour tissues as well as in nearby normal epithelial cells [33]; therefore, toxicity to nearby normal cells is possible. Additionally, because bone marrow haematopoietic stem cells, germ cells, and intestinal epithelium cells in humans maintain active proliferation, some QCC-targeting agents that induce and maintain proliferating cells in quiescence through the regulation of cyclins may have inhibitory effects on these actively proliferating cells.

The biological and molecular characteristics of QCCS require further clarification. Bioinformatic analysis of the genomic, transcriptome, proteomic, and metabolomic differences between QCCs and proliferative cancer cells may reveal the potential regulatory genes and signalling pathways involved in QCC survival and on/off switching of the quiescent state. Accurate in vivo and in vitro QCC models can be developed by regulating the identified on/off-switch genes controlling the transition of cancer cells into and out of quiescence. Among the complex signals that control QCC survival and proliferation, key proteins that are clinically correlated with patient outcomes must be identified. Moreover, whether these proteins act similarly across different cancer cells (e.g., cells at the tumour primary site vs. secondary sites, DTCs, or CTCs) must be clarified. Another challenge is determining the roles of key proteins in microenvironmental niches. Environmental and lifestyle factors, such 
as smoking, diet, nutrition, and physical activity, have been reported to influence the tumour microenvironment, thereby affecting cancer occurrence and progression $[113,114]$. However, the exact targets influenced by the environment are unclear. Exploring whether these acquired factors modulate the survival and proliferation of QCCs should prove interesting. These findings will be important, because they might potentially be modified to suppress the clinical course of cancer and potentiate the response to therapy.

\section{CONFLICTS OF INTEREST}

The authors declare no conflicts of interest.

\section{AUTHOR CONTRIBUTIONS}

Z.X. and Q.D. structured the manuscript. W.N.N.N. and Z.X. wrote the manuscript and prepared the figures, to which Y.L. and M.L. contributed. Q.D., M.Y., and T.L. edited the manuscript. H.X. provided the guidance throughout the preparation of the manuscript.

\section{ABBREVIATIONS}

ALL, acute lymphoblastic leukaemia; APC, anaphasepromoting complex; ATG, autophagy-related genes; ATRA, all-trans retinoic acid; Bcl-2, B-cell lymphoma-2; $B M P$, bone morphogenetic protein; $C D K$, cyclin-dependent kinase; CDKIs, cyclin-dependent kinase inhibitors; CML, chronic myeloid leukaemia; CTCs, circulating tumour cells; CXCL12, C-X-C motif chemokine ligand-12; DDR1, discoidin domain receptor tyrosine kinase; $D L B C L$, diffuse large B-cell lymphoma; DTCs, disseminated tumour cells; DYRK1B, dual specificity tyrosine phosphorylation-regulated kinase 1B; ECM, extracellular matrix; $E Z H$, enhancer of Zeste; FACT, facilitates chromatin transcription factor; FAK, focal adhesion kinase; FBXW7, F-box with 7 tandem WD40; GIST, gastrointestinal stromal tumours; GUTK, guttiferone K; IAP, inhibitor of apoptosis; InsP3Rs, inositol 1,4,5-trisphosphate receptors; LSC, leukaemia stem cells; IncRNAs, long non-coding RNAs; $M C L$, mantle cell lymphoma; miRNAs, microRNAs; MuvB, multi-vulval class $B$; ncRNA, non-coding RNA; NK, natural killer; NSCLC, nonsmall cell lung cancer NSCLC; ORR, objective response rate; OXPHOS, oxidative phosphorylation; PCCs, proliferating cancer cells; PDAC, pancreatic ductal adenocarcinoma; PFS, progression free survival; PRC2, Polycomb repressive complex 2; PSC, pancreatic stellate cells; RANKL, receptor activation of NF- $\kappa \beta$ ligand; QCCs, quiescent cancer cells; $\mathrm{Rb}$, retinoblastoma protein; ROS, reactive oxygen species; SCF, SKP1/Cullin 1/F-box; SFRP4, secreted frizzled-related protein 4; SKP2, S-phase kinase-associated protein 2; TGF 32 , transforming growth factor- $\beta 2$.

\section{ACKNOWLEDGMENTS}

This work was supported by the National Natural Science Foundation of China (grant Nos. 81803571 and 81973438) and the Key-Area Research and Development Program of Guangdong Province (grant No. 2020B1111110003).

\section{REFERENCES}

[1] Phan TG, Croucher PI: The Dormant Cancer Cell Life Cycle. Nature Reviews Cancer 2020, 20(7):398-411.

[2] Endo $\mathrm{H}$, Inoue M: Dormancy in Cancer. Cancer Science 2019, 110(2):474-480.

[3] Yeh AC, Ramaswamy S: Mechanisms of Cancer Cell Dormancy--Another Hallmark of Cancer? Cancer Research 2015, 75(23):5014-5022.

[4] Yao G: Modelling Mammalian Cellular Quiescence. Interface Focus 2014, 4(3):34458-34474.

[5] Chistiakov DA, Chekhonin VP: Circulating Tumor Cells and Their Advances to Promote Cancer Metastasis and Relapse, with Focus on Glioblastoma Multiforme. Experimental and Molecular Pathology 2018, 105(2): 166-174.

[6] Widner DB, Park SH, Eber MR, Shiozawa Y: Interactions Between Disseminated Tumor Cells and Bone Marrow Stromal Cells Regulate Tumor Dormancy. Current Osteoporosis Reports 2018, 16(5):596-602.

[7] Nik Nabil WN, Xi Z, Song Z, Jin L, Zhang XD, Zhou H, et al.: Towards a Framework for Better Understanding of Quiescent Cancer Cells. Cells 2021, 10(3):562.

[8] Gao XL, Zhang M, Tang YL, Liang XH: Cancer Cell Dormancy: Mechanisms and Implications of Cancer Recurrence and Metastasis. OncoTargets and Therapy 2017, 10:5219-5228.

[9] Sosa MS, Bragado P, Aguirre-Ghiso JA: Mechanisms of Disseminated Cancer Cell Dormancy: An Awakening Field. Nature Reviews Cancer 2014, 14(9):611-622.

[10] Chou A, Froio D, Nagrial AM, Parkin A, Murphy KJ, Chin VT, et al.: Tailored First-line and Second-line CDK4targeting Treatment Combinations in Mouse Models of Pancreatic Cancer. Gut 2018, 67(12):2142-2155.

[11] Morris-Hanon O, Marazita MC, Romorini L, Isaja L, Fernandez-Espinosa DD, Sevlever GE, et al.: Palbociclib Effectively Halts Proliferation but Fails to Induce Senescence in Patient-Derived Glioma Stem Cells. Molecular Neurobiology 2019, 56(11):7810-7821.

[12] Grande E, Teulé $A$, Alonso-Gordoa T, Jiménez-Fonseca $P$, Benavent M, Capdevila J, et al.: The PALBONET Trial: A Phase II Study of Palbociclib in Metastatic Grade 1 and 2 Pancreatic Neuroendocrine Tumors (GETNE-1407). The Oncologist 2020, 25(9):e745-e1265.

[13] Dowless $M$, Lowery $C D$, Shackleford T, Renschler $M$, Stephens J, Flack $R$, et al.: Abemaciclib is Active in Preclinical Models of Ewing Sarcoma via Multipronged Regulation of Cell Cycle, DNA Methylation, and Interferon Pathway Signaling. Clinical Cancer Research : An Official Journal of the American Association for Cancer Research 2018, 24(23):6028-6039.

[14] Liu Y, Perdreau SA, Chatterjee P, Wang L, Kuan SF, Duensing A: Imatinib Mesylate Induces Quiescence in Gastrointestinal Stromal Tumor Cells Through the CDH1SKP2-p27Kip1 Signaling Axis. Cancer Research 2008, 68(21):9015-9023.

[15] Boichuk S, Parry JA, Makielski KR, Litovchick L, Baron JL, Zewe JP, et al.: The DREAM Complex Mediates GIST Cell Quiescence and is a Novel Therapeutic Target to Enhance Imatinib-induced Apoptosis. Cancer Research 2013, 73(16):5120-5129. 
[16] Gupta A, Roy S, Lazar AJ, Wang WL, McAuliffe JC, Reynoso D, et al.: Autophagy Inhibition and Antimalarials Promote Cell Death in Gastrointestinal Stromal Tumor (GIST). Proceedings of the National Academy of Sciences of the United States of America 2010, 107(32): 14333-14338.

[17] Shankar E, Franco D, Iqbal O, Moreton S, Kanwal R, Gupta S: Dual Targeting of EZH2 and Androgen Receptor as a Novel Therapy for Castration-resistant Prostate Cancer. Toxicology and Applied Pharmacology 2020, 404:115200.

[18] Gulati N, Béguelin W, Giulino-Roth L: Enhancer of Zeste Homolog 2 (EZH2) Inhibitors. Leukemia \& Lymphoma 2018, 59(7):1574-1585.

[19] Kagiyama Y, Fujita S, Shima Y, Yamagata K, Katsumoto T, Nakagawa M, et al.: CDKN1C-mediated Growth Inhibition by an EZH1/2 Dual Inhibitor Overcomes Resistance of Mantle Cell Lymphoma to Ibrutinib. Cancer Science 2021, 112(6):2314-2324.

[20] Cortes E, Lachowski D: Retinoic Acid Receptor- $\beta$ Is Downregulated in Hepatocellular Carcinoma and Cirrhosis and Its Expression Inhibits Myosin-Driven Activation and Durotaxis in Hepatic Stellate Cells. Hepatology 2019, 69(2):785-802

[21] Froeling F, Chelala C, Clevers H, Hart I, Kocher H: Retinoic Acid-induced Stellate Cell Quiescence Results in Sfrp4 Secretion which Abrogates Wnt- $\beta$-catenin Signalling Pathway Modulating Human Pancreatic Tumour cell Behaviour. Gastroenterology 2011, 140(5, Suppl 1):S-156-S-157

[22] Ookura M, Fujii T, Yagi H, Ogawa T, Kishi S, Hosono N et al.: YM155 Exerts Potent Cytotoxic Activity Against Quiescent (G(0)/G(1)) Multiple Myeloma and Bortezomib Resistant Cells via Inhibition of Survivin and Mcl-1. Oncotarget 2017, 8(67):111535-111550.

[23] Huang YT, Cheng CC, Lin TC, Chiu TH, Lai PC: Therapeutic Potential of Sepantronium Bromide YM155 in Gemcitabine-resistant Human Urothelial Carcinoma Cells. Oncology Reports 2014, 31(2):771-780.

[24] Xi Z, Yao M, Li Y, Xie C, Holst J, Liu T, et al.: Guttiferone K Impedes Cell Cycle Re-entry of Quiescent Prostate Cancer Cells via Stabilization of FBXW7 and Subsequent c-MYC Degradation. Cell Death \& Disease 2016, 7(6):e2252.

[25] Jiang $X$, Li Y, Feng J-L, Nik Nabil WN, Wu R, Lu Y, et al.: Safrana I Prevents Prostate Cancer Recurrence by Blocking the Re-activation of Quiescent Cancer Cells via Downregulation of S-Phase Kinase-Associated Protein 2. Frontiers in Cell and Developmental Biology 2020, 8:1553.

[26] Zhang X, Fryknas M, Hernlund E, Fayad W, De Milito $A$, Olofsson $\mathrm{MH}$, et al.: Induction of Mitochondrial Dysfunction as a Strategy for Targeting Tumour Cells in Metabolically Compromised Microenvironments. Nature Communications 2014, 5:3295.

[27] Maeda Y, Kikuchi R, Kawagoe J, Tsuji T, Koyama N, Yamaguchi K, et al.: Anti-cancer Strategy Targeting the Energy Metabolism of Tumor Cells Surviving a Lownutrient Acidic Microenvironment. Molecular Metabolism 2020, 42:101093.

[28] Pei XY, Dai Y, Youssefian LE, Chen S, Bodie WW, Takabatake $Y$, et al.: Cytokinetically Quiescent (G0/G1) Human Multiple Myeloma Cells are Susceptible to Simultaneous Inhibition of Chk1 and MEK1/2. Blood 2011, 118(19): 5189-5200.

[29] Kumar H, Chattopadhyay S, Das N, Shree S, Patel D, Mohapatra J, et al.: Leprosy Drug Clofazimine Activates
Peroxisome Proliferator-activated Receptor- $\gamma$ and Synergizes with Imatinib to Inhibit Chronic Myeloid Leukemia Cells. Haematologica 2020, 105(4):971-986.

[30] Ewton DZ, Hu J, Vilenchik M, Deng X, Luk KC, Polonskaia A, et al.: Inactivation of Mirk/Dyrk1b Kinase Targets Quiescent Pancreatic Cancer Cells. Molecular Cancer Therapeutics 2011, 10(11):2104-2114.

[31] Deng X, Hu J, Cunningham MJ, Friedman E: Mirk Kinase Inhibition Targets Ovarian Cancer Ascites. Genes \& cancer 2014, 5(5-6):201-211.

[32] Deng X, Friedman E: Mirk Kinase Inhibition Blocks the In Vivo Growth of Pancreatic Cancer Cells. Genes \& Cancer 2014, 5(9-10):337-347

[33] Friedman E: Mirk/dyrk1B Kinase in Ovarian Cancer. International Journal of Molecular Sciences 2013, 14(3):5560-5575.

[34] Malumbres M: Chapter 4 - Control of the cell cycle. In Abeloff's Clinical Oncology. 5th edition. Edited by Niederhuber J, Armitage J, Doroshow J, Kastan M, Tepper J. Philadelphia: Elsevier Inc; 2014:52-68.e56.

[35] So WK, Cheung TH: Molecular Regulation of Cellular Quiescence: A Perspective from Adult Stem Cells and Its Niches. In Cellular Quiescence Methods in Molecular Biology. Volume 1686. Edited by Daniel Lacorazza H. New York: Humana Press; 2018:1-25.

[36] Schade AE, Oser MG, Nicholson HE, DeCaprio JA: Cyclin D-CDK4 Relieves Cooperative Repression of Proliferation and Cell Cycle Gene Expression by DREAM and RB. Oncogene 2019, 38(25):4962-4976.

[37] Coller HA: What's Taking so Long? S-phase Entry from Quiescence Versus Proliferation. Nature Reviews Molecular Cell Biology 2007, 8(8):667-670.

[38] Hateboer G, Wobst A, Petersen BO, Le Cam L, Vigo E, Sardet C, Helin K: Cell Cycle-regulated Expression of Mammalian CDC6 is Dependent on E2F. Molecular and Cellular Biology 1998, 18(11):6679-6697.

[39] Petrakis TG, Vougas K, Gorgoulis VG: Cdc6: a multifunctional molecular switch with critical role in carcinogenesis. Transcription 2012, 3(3):124-129.

[40] Prekovic S, Schuurman K, Mayayo-Peralta I, Manjón AG, Buijs M, Yavuz S, et al.: Glucocorticoid Receptor Triggers a Reversible Drug-tolerant Dormancy State with Acquired Therapeutic Vulnerabilities in Lung Cancer. Nature Communications 2021, 12(1):4360.

[41] Zou T, Lin Z: The Involvement of Ubiquitination Machinery in Cell Cycle Regulation and Cancer Progression. International Journal of Molecular Sciences 2021, 22(11):5754.

[42] Suzuki A, Hayashida $M$, Ito $T$, Kawano $H$, Nakano $T$, Miura $M$, et al.: Survivin Initiates Cell Cycle Entry by the Competitive Interaction with Cdk4/p16(INK4a) and Cdk2/cyclin E Complex Activation. Oncogene 2000, 19(29):3225-3234

[43] Varlet E, Ovejero S, Martinez AM, Cavalli G, Moreaux J: Role of Polycomb Complexes in Normal and Malignant Plasma Cells. International Journal of Molecular Sciences 2020, 21(21):8047.

[44] Nakagawa S, Okabe H, Sakamoto Y, Hayashi H, Hashimoto D, Yokoyama N, et al.: Enhancer of Zeste Homolog 2 (EZH2) Promotes Progression of Cholangiocarcinoma Cells by Regulating Cell Cycle and Apoptosis. Annals of Surgical Oncology 2013, 20(Suppl 3):S667-S675.

[45] Yin Y, Qiu S, Peng Y: Functional Roles of Enhancer of Zeste Homolog 2 in Gliomas. Gene 2016, 576(1 Pt 2):189-194. 
[46] García-Gutiérrez L, Delgado MD, León J: MYC Oncogene Contributions to Release of Cell Cycle Brakes. Genes 2019, 10(3):244.

[47] Bi L, Xie C, Yao M, Thae Hnit SS, Vignarajan S, Wang Y, et al.: The Histone Chaperone Complex FACT Promotes Proliferative Switch of G0 Cancer Cells. International Journal of Cancer 2019, 145(1):164-178.

[48] Bretones G, Delgado MD, Leon J: Myc and Cell Cycle Control. Biochimica et Biophysica Acta 2015, 1849(5):506-516.

[49] Ivanovska I, Ball AS, Diaz RL, Magnus JF, Kibukawa M, Schelter JM, et al.: MicroRNAs in the miR-106b Family Regulate $\mathrm{p} 21 / \mathrm{CDKN} 1 \mathrm{~A}$ and Promote Cell Cycle Progression. Molecular and Cellular Biology 2008, 28(7):2167-2174.

[50] Bueno MJ, Malumbres M: MicroRNAs and the Cell Cycle. Biochimica et Biophysica Acta 2011, 1812(5):592-601.

[51] Massague J: G1 Cell-cycle Control and Cancer. Nature 2004, 432(7015):298-306.

[52] La T, Chen S, Guo T, Zhao XH, Teng L, Li D, et al.: Visualization of Endogenous p27 and Ki67 Reveals the Importance of a c-Myc-driven Metabolic Switch in Promoting Survival of Quiescent Cancer Cells. Theranostics 2021, 11(19):9605-9622.

[53] Sun CC, Qu XJ, Gao ZH: Integrins: Players in Cancer Progression and Targets in Cancer Therapy. Anti-cancer Drugs 2014, 25(10):1107-1121.

[54] Tai YL, Chen LC, Shen TL: Emerging Roles of Focal Adhesion Kinase in Cancer. BioMed Research International 2015, 2015:690690.

[55] Aguirre-Ghiso JA: Inhibition of FAK Signaling Activated by Urokinase Receptor Induces Dormancy in Human Carcinoma Cells In Vivo. Oncogene 2002, 21(16):2513-2524.

[56] Bildik G, Liang X, Sutton MN, Bast RC, Jr., Lu Z: DIRAS3: An Imprinted Tumor Suppressor Gene that Regulates RAS and PI3K-driven Cancer Growth, Motility, Autophagy, and Tumor Dormancy. Molecular Cancer Therapeutics 2022, 21(1):25-37.

[57] Sharma S, Pei X, Xing F, Wu SY, Wu K, Tyagi A, et al.: Regucalcin Promotes Dormancy of Prostate Cancer. Oncogene 2021, 40(5):1012-1026.

[58] Ho JS, Ma W, Mao DY, Benchimol S: p53-Dependent Transcriptional Repression of c-myc is Required for G1 Cell Cycle Arrest. Molecular and Cellular Biology 2005, 25(17):7423-7431.

[59] Sosa MS, Avivar-Valderas A, Bragado P, Wen HC, AguirreGhiso JA: ERK1/2 and p38alpha/beta Signaling in Tumor Cell Quiescence: Opportunities to Control Dormant Residual Disease. Clinical Cancer Research : an Official Journal of the American Association for Cancer Research 2011, 17(18):5850-5857.

[60] Sylvestre Y, De Guire V, Querido E, Mukhopadhyay UK, Bourdeau V, Major F, et al.: An E2F/miR-20a Autoregulatory Feedback Loop. The Journal of Biological Chemistry 2007, 282(4):2135-2143.

[61] Becker W: A Wake-up Call to Quiescent Cancer Cells Potential use of DYRK1B Inhibitors in Cancer Therapy. The FEBS Journal 2018, 285(7):1203-1211.

[62] Sadasivam S, DeCaprio JA: The DREAM Complex: Master Coordinator of Cell Cycle-dependent Gene Expression. Nature Reviews Cancer 2013, 13(8):585-595.

[63] Grillone K, Riillo C, Scionti F, Rocca R, Tradigo G, Guzzi $\mathrm{PH}$, et al.: Non-coding RNAs in Cancer: Platforms and Strategies for Investigating the Genomic "Dark Matter".
Journal of Experimental \& Clinical Cancer Research: CR 2020, 39(1):117.

[64] Kitagawa M, Kitagawa K, Kotake Y, Niida H, Ohhata T: Cell Cycle Regulation by Long Non-coding RNAs. Cellular and Molecular Life Sciences : CMLS 2013, 70(24):4785-4794.

[65] Raffel S, Trumpp A: miR-126 Drives Quiescence and Self-renewal in Leukemic Stem Cells. Cancer cell 2016, 29(2):133-135.

[66] Bueno MJ, Gomez de Cedron M, Laresgoiti U, FernandezPiqueras J, Zubiaga AM, Malumbres M: Multiple E2Finduced microRNAs Prevent Replicative Stress in Response to Mitogenic Signaling. Molecular and Cellular Biology 2010, 30(12):2983-2995.

[67] Silvestri G, Trotta R, Stramucci L, Ellis JJ, Harb JG, Neviani $P$, et al.: Persistence of Drug-Resistant Leukemic Stem Cells and Impaired NK Cell Immunity in CML Patients Depend on MIR300 Antiproliferative and PP2A-Activating Functions. Blood Cancer Discovery 2020, 1(1):48-67.

[68] La T, Liu GZ, Farrelly M, Cole N, Feng YC, Zhang YY, et al.: A p53-responsive microRNA Network Promotes Cancer Cell Quiescence. Cancer Research 2018, 78(23): 6666-6679.

[69] Liu Y, Zhang P, Wu Q, Fang H, Wang $Y$, Xiao $Y$, et al.: Long Non-coding RNA NR2F1-AS1 Induces Breast Cancer Lung Metastatic Dormancy by Regulating NR2F1 and $\Delta \mathrm{Np} 63$. Nature Communications 2021, 12(1):5232.

[70] Viale A, Draetta GF: Metabolic Features of Cancer Treatment Resistance. Recent Results in Cancer Research Fortschritte der Krebsforschung Progres Dans les Recherches sur le Cancer 2016, 207:135-156.

[71] Liu Z, Sun Y, Tan S, Liu L, Hu S, Huo H, et al.: Nutrient Deprivation-related OXPHOS/glycolysis Interconversion via HIF-1 $\alpha /$ C-MYC Pathway in U251 Cells. Tumour Biology: The Journal of the International Society for Oncodevelopmental Biology and Medicine 2016, 37(5):6661-6671.

[72] Valle S, Alcalá S, Martin-Hijano L, Cabezas-Sáinz P, Navarro D, Muñoz ER, et al.: Exploiting Oxidative Phosphorylation to Promote the Stem and Immunoevasive Properties of Pancreatic Cancer Stem Cells. Nature Communications 2020, 11(1):5265.

[73] Shahar N, Larisch S: Inhibiting the Inhibitors: Targeting Anti-apoptotic Proteins in Cancer and Therapy Resistance. Drug Resistance Updates: Reviews and Commentaries in Antimicrobial and Anticancer Chemotherapy 2020, $52: 100712$

[74] Kiraz Y, Adan A, Kartal Yandim M, Baran Y: Major Apoptotic Mechanisms and Genes Involved in Apoptosis. Tumour Biology: The Journal of the International Society for Oncodevelopmental Biology and Medicine 2016, 37(7):8471-8486.

[75] Akkoc Y, Peker N, Akcay A, Gozuacik D: Autophagy and Cancer Dormancy. Frontiers in Oncology 2021, 11:627023.

[76] Amaravadi RK, Kimmelman AC, Debnath J: Targeting Autophagy in Cancer: Recent Advances and Future Directions. Cancer Discovery 2019, 9(9):1167-1181.

[77] Vera-Ramirez L, Vodnala SK, Nini R, Hunter KW, Green JE: Autophagy Promotes the Survival of Dormant Breast Cancer Cells and Metastatic Tumour Recurrence. Nature Communications 2018, 9(1):1944.

[78] Lu Z, Luo RZ, Lu Y, Zhang X, Yu Q, Khare S, et al.: The Tumor Suppressor Gene ARHI Regulates Autophagy and Tumor Dormancy in Human Ovarian Cancer Cells. The Journal of Clinical Investigation 2008, 118(12):3917-3929. 
[79] You B, Xia T, Gu M, Zhang Z, Zhang Q, Shen J, et al.: AMPK-mTOR-mediated Activation of Autophagy Promotes Formation of Dormant Polyploid Giant Cancer Cells. Cancer Research 2021. [Epub ahead of print]

[80] Fiore A, Ribeiro PF, Bruni-Cardoso A: Sleeping Beauty and the Microenvironment Enchantment: Microenvironmental Regulation of the Proliferation-quiescence Decision in Normal Tissues and in Cancer Development. Frontiers in Cell and Developmental Biology 2018, 6:59.

[81] Di Martino JS, Nobre AR, Mondal C, Taha I, Farias EF, Fertig EJ, et al.: A Tumor-derived Type III Collagen-rich ECM Niche Regulates Tumor Cell Dormancy. Nature Cancer 2022, 3(1):90-107.

[82] Singh DK, Patel VG, Oh WK, Aguirre-Ghiso JA: Prostate Cancer Dormancy and Reactivation in Bone Marrow. Journal of Clinical Medicine 2021, 10(12):2648.

[83] Li B, Huang Y, Ming H, Nice EC, Xuan R, Huang C: Redox Control of the Dormant Cancer Cell Life Cycle. Cells 2021, 10(10):2707.

[84] Li X, Yang J, Bao M, Zeng K, Fu S, Wang C, Ye L: Wnt Signaling in Bone Metastasis: Mechanisms and Therapeutic Opportunities. Life Sciences 2018, 208:33-45.

[85] Lo YH, Noah TK, Chen MS, Zou W, Borras E, Vilar E, et al.: SPDEF Induces Quiescence of Colorectal Cancer Cells by Changing the Transcriptional Targets of $\beta$-catenin. Gastroenterology 2017, 153(1):205-218.e208.

[86] Zhang B, Nguyen LXT, Li L, Zhao D, Kumar B, Wu H, et al.: Bone Marrow Niche Trafficking of miR-126 Controls the Self-renewal of Leukemia Stem Cells in Chronic Myelogenous Leukemia. Nature Medicine 2018, 24(4):450-462.

[87] Patel SA, Meyer JR, Greco SJ, Corcoran KE, Bryan M, Rameshwar P: Mesenchymal Stem Cells Protect Breast Cancer Cells Through Regulatory $T$ cells: Role of Mesenchymal Stem Cell-derived TGF-beta. Journal of Immunology (Baltimore, Md : 1950) 2010, 184(10):5885-5894.

[88] Bliss SA, Sinha G, Sandiford OA, Williams LM, Engelberth DJ, Guiro K, et al.: Mesenchymal Stem Cell-derived Exosomes Stimulate Cycling Quiescence and Early Breast Cancer Dormancy in Bone Marrow. Cancer Research 2016, 76(19):5832-5844.

[89] Sandiford OA, Donnelly RJ, El-Far MH, Burgmeyer LM, Sinha G, Pamarthi SH, et al.: Mesenchymal Stem Cell-Secreted Extracellular Vesicles Instruct Stepwise Dedifferentiation of Breast Cancer Cells into Dormancy at the Bone Marrow Perivascular Region. Cancer Research 2021, 81(6):1567-1582.

[90] Correia AL, Guimaraes JC, Auf der Maur P, De Silva D, Trefny MP, Okamoto R, et al.: Hepatic Stellate Cells Suppress NK Cell-sustained Breast Cancer Dormancy. Nature 2021, 594(7864):566-571.

[91] Damen MPF, van Rheenen J, Scheele C: Targeting Dormant Tumor Cells to Prevent Cancer Recurrence. The FEBS Journal 2021, 288(21):6286-6303.

[92] Recasens A, Munoz L: Targeting Cancer Cell Dormancy. Trends Pharmacol Sci 2019, 40(2):128-141.

[93] Hendrychová D, Jorda R, Kryštof V: How Selective are Clinical CDK4/6 Inhibitors? Medicinal Research Reviews 2021, 41(3):1578-1598.

[94] Marra A, Curigliano G: Are all Cyclin-dependent Kinases 4/6 Inhibitors Created Equal? NPJ Breast Cancer 2019, $5: 27$.
[95] Hamilton E, Infante JR: Targeting CDK4/6 in Patients with Cancer. Cancer Treatment Reviews 2016, 45:129-138.

[96] National Comprehensive Cancer Network (NCCN): Breast Cancer - NCCN Evidence Block, Version 4. NCCN Clinical Practice Guidelines in Oncology. 2021:241.

[97] Vijayaraghavan S, Moulder S, Keyomarsi K, Layman RM: Inhibiting CDK in Cancer Therapy: Current Evidence and Future Directions. Targeted Oncology 2018, 13(1):21-38.

[98] Flynn JP, Gerriets V: Imatinib. In: StatPearls. Treasure Island (FL): StatPearls Publishing. Copyright () 2021, StatPearls Publishing LLC.; 2021.

[99] Essat M, Cooper K: Imatinib as Adjuvant Therapy for Gastrointestinal Stromal Tumors: A Systematic Review. International Journal of Cancer 2011, 128(9): 2202-2214.

[100] Raut CP, Espat NJ, Maki RG, Araujo DM, Trent J, Williams TF, et al.: Efficacy and Tolerability of 5-Year Adjuvant Imatinib Treatment for Patients With Resected Intermediate- or High-Risk Primary Gastrointestinal Stromal Tumor: The PERSIST-5 Clinical Trial. JAMA Oncology 2018, 4(12):e184060.

[101] Li C, Wang Y, Gong Y, Zhang T, Huang J, Tan Z, et al.: Finding an Easy Way to Harmonize: A Review of Advances in Clinical Research and Combination Strategies of EZH2 Inhibitors. Clinical Epigenetics 2021, 13(1):62

[102] Coombs CC, Tavakkoli M, Tallman MS: Acute Promyelocytic Leukemia: Where did we Start, where are we now, and the Future. Blood Cancer Journal 2015, 5:e304.

[103] Han X, Li Y, Xu Y, Zhao X, Zhang Y, Yang X, et al.: Reversal of Pancreatic Desmoplasia by Re-educating Stellate Cells with a Tumour Microenvironment-activated Nanosystem. Nature Communications 2018, 9(1):3390.

[104] Kocher HM, Basu B, Froeling FEM, Sarker D, Slater S, Carlin D, et al.: Phase I Clinical Trial Repurposing All-trans Retinoic Acid as a Stromal Targeting Agent for Pancreatic Cancer. Nature Communications 2020, 11(1):4841.

[105] Li F, Aljahdali I, Ling X: Cancer Therapeutics Using Survivin BIRC5 as a Target: What can we do After Over Two Decades of Study? Journal of Experimental \& Clinical Cancer Research: CR 2019, 38(1):368.

[106] Kan WL, Yin C, Xu HX, Xu G, To KK, Cho CH, et al.: Antitumor Effects of Novel Compound, Guttiferone K, on Colon Cancer by p21Waf1/Cip1-mediated G(0)/G(1) Cell Cycle Arrest and Apoptosis. International Journal of Cancer 2013, 132(3):707-716.

[107] Mody K, Mansfield AS, Vemireddy L, Nygren P, Gulbo J, Borad M: A Phase I Study of the Safety and Tolerability of VLX600, an Iron Chelator, in Patients with Refractory Advanced Solid Tumors. Investigational New Drugs 2019, 37(4):684-692.

[108] Zhu Y, Chen H, Boulton S, Mei F, Ye N, Melacini G, et al.: Biochemical and Pharmacological Characterizations of ESI-09 Based EPAC Inhibitors: Defining the ESI-09 "Therapeutic Window". Scientific Reports 2015, 5:9344.

[109] Markham A, Keam SJ: Selumetinib: First Approval. Drugs 2020, 80(9):931-937.

[110] Holkova B, Zingone A, Kmieciak M, Bose P, Badros AZ, Voorhees PM, et al.: A Phase II Trial of AZD6244 (Selumetinib, ARRY-142886), an Oral MEK1/2 Inhibitor, in Relapsed/Refractory Multiple Myeloma. Clinical 
Acta

Materia

\section{Review}

Cancer Research: An Official Journal of the American Association for Cancer Research 2016, 22(5):1067-1075.

[111] Fujita S, Honma D, Adachi N, Araki K, Takamatsu E, Katsumoto T, et al.: Dual Inhibition of EZH1/2 Breaks the Quiescence of Leukemia Stem Cells in Acute Myeloid Leukemia. Leukemia 2018, 32(4):855-864.

[112] Barkan D, Kleinman $H$, Simmons JL, Asmussen $H$, Kamaraju AK, Hoenorhoff MJ, et al.: Inhibition of Metastatic Outgrowth from Single Dormant Tumor Cells by Targeting the Cytoskeleton. Cancer Research 2008, 68(15):6241-6250.

[113] Hayashi T, Fujita K, Hayashi Y, Hatano K, Kawashima A, McConkey DJ, et al.: Mutational Landscape and Environmental Effects in Bladder Cancer. International Journal of Molecular Sciences 2020, 21(17):6072.

[114] Xu Y, Rogers CJ: Physical Activity and Breast Cancer Prevention: Possible Role of Immune Mediators. Frontiers in Nutrition 2020, 7:557997. 